SEX WORKERS

\title{
Chlamydia trachomatis in female sex workers in Belgium: 1998-2003
}

\author{
R P Mak, L Van Renterghem, A Traen
}

Sex Transm Infect 2005;81:89-90. doi: 10.1136/sti.2004.010272

\begin{abstract}
Objective: We analysed the results of a 6 year screening period for Chlamydia trachomatis in a group of female sex workers (FSW) of all ages in Ghent, Belgium.

Methods: They were tested in the context of an outreach health programme for sex workers. C trachomatis was tested by Cobas Amplicor CT/NG PCR.

Results: In the 6 year period, 1643 tests were performed on 950 different sex workers (nationality: Belgian $60.3 \%$, other western European (mostly French) $21.0 \%$, African 12.4\%, eastern European 3.0\%, other 3.3\%; workplace: bar/sauna $49.0 \%$, private homes $31.8 \%$, windows $18.2 \%$, and escorts $1.0 \%$ ). Baseline prevalence (only considering results of first test) was $70 / 950$ or $7.4 \%$ (95\% Cl 5.7 to 9.0$)$. The incidence rate was 98 episodes in 1347 person years or $7.3 / 100$ person years (95\% Cl 5.9 to 8.7$)$. There was a strong age effect. There was no clear relation with nationality or the workplace.

Conclusions: The prevalence was higher than in general populations selected in Belgium, Britain, and the Netherlands. Since younger age is a risk factor for $C$ trachomatis, it is very important to contact these women as soon as possible when they enter the trade. General screening for $C$ trachomatis in young women is not common practice in Belgium. Sex workers often do not tell doctors about their work and will therefore not be screened unless in the context of specific outreach projects.
\end{abstract}

nfections by Chlamydia trachomatis are an important public health problem since they can cause complications such as pelvic inflammatory disease (PID), chronic pelvic pain, ectopic pregnancy and infertility. ${ }^{1}$ Screening for genital $C$ trachomatis infection is considered as effective to reduce these complications. ${ }^{2}$ In this study we analysed the results of a 6 year screening period for $C$ trachomatis in a group of female sex workers (FSW) of all ages in Ghent, Belgium.

\section{METHODS}

In the context of an outreach health programme for sex workers in Ghent, Belgium, and surroundings, ${ }^{3} \mathrm{C}$ trachomatis testing is performed in the following situations: on first contact, as part of basic STI screening; after a perceived riskfor example, condom breakage, when signs and symptoms are present. Those positive were treated or referred for treatment. The importance of partner treatment was emphasised and on many occasions we handed out a prescription for the epidemiological treatment of private partners. Since 1998, C trachomatis has been tested by the Cobas Amplicor CT/ NG PCR (Roche Diagnostics) done on first void urine samples according to the manufacturer's instructions.

When comparing the results with other studies, it was adjusted for age.

\section{RESULTS}

In a 6 year period, 1643 tests were done on urine specimens from 950 different sex workers. Most tests were performed on non-symptomatic women. The nationality of the sex workers is Belgian 60.3\%, other western European (mostly French) $21.0 \%$, African $8.2 \%$, Moroccan $4.2 \%$, eastern European $3.0 \%$ and other $3.3 \%$. Their workplace is bar/sauna $49.0 \%$, private homes $31.8 \%$, windows $18.2 \%$, and escorts $1.0 \%$.

When only the result of the first test taken by the project is considered, we find 70 positive tests in 950 women, or a baseline prevalence of $7.4 \%$ (95\% CI: 5.7 to 9.0 ).

The age when the first test was positive is shown in table 1. There is a strong age factor.

There is no clear relation to nationality or the workplace.

Considering all tests, one positive test was found in 75 people, two positive tests in 11 , three positive tests in one person, and four positive tests in one, bringing the total of positive tests to 104. When reviewing individual case histories, we calculated that the 104 positive tests reflected at least 98 different $C$ trachomatis episodes.

We can estimate the number of person years by counting the number of years in which at least one test was carried out on a woman. This gives us 98 episodes in 1347 person years or an incidence rate of 7.3/100 person years (CI95\%: 5.9 to 8.7). The evolution over time is given in table 2 .

\section{DISCUSSION}

The number of people tested for $C$ trachomatis rose gradually. This was the result of the extension of the team in 2000 , enlarging the capacity for testing and to the phenomenon of increased testing after condom failure, which was actively promoted by the project. The development of reliable PCR tests on urine lowered the barrier for screening, especially in this population, where most tests are sampled in outreach conditions.

To estimate the baseline prevalence of $C$ trachomatis of the sex workers in the area we analysed the results of those who had their first test in the project at any moment in the 6 year period of observation. These women were new to the project and represented sex workers who were not yet influenced by the project. Every year, more than half of all sex workers visited by the project are new, which reflects the high turnover in this group.

To estimate the incidence rate, we assumed that when someone was tested in a year, this counted for one person year of observation. If someone had more than one positive test, the decision was made whether or not this reflected one or more episodes.

Incidence could be underestimated if the practice of self treatment or prophylactic treatment is widely spread. In our study with mainly European women, these practices are rare and will therefore hardly influence our estimate.

The baseline prevalence rate of $7.4 \%$ (95\% CI: 5.7 to 9.0 ) was lower than in immigrant sex workers $(n=101)$ in Italy ${ }^{4}$ ( $11 \%$ after correction for age), and in registered sex workers $(\mathrm{n}=354)$ in $\operatorname{Mexico}^{5}$ ( $14.5 \%$ after adjustment for age). It was

Abbreviations: FSW, female sex workers; PCR, polymerase chain reaction; PID, pelvic inflammatory disease 
Table 1 Positive $C$ trachomatis on first test of FSW in Belgium in relation to age $(n=920)$

\begin{tabular}{lllll}
\hline Age group & Test positive $(\mathbf{n})$ & $(\%)$ & $95 \% \mathrm{Cl}$ & Total \\
\hline$<20$ & 15 & 15.0 & 8.0 to 22.0 & 100 \\
$21-29$ & 40 & 8.3 & 5.0 to 10.7 & 484 \\
$>29$ & 12 & 3.6 & 1.6 to 5.6 & 336 \\
Total & 67 & 7.3 & 5.6 to 9.0 & $920^{*}$ \\
\hline$\chi^{2}: p<0.001$. & & & \\
${ }^{*}$ No age available for 30 women. & & & \\
\hline
\end{tabular}

Table 2 Incidence rates for C trachomatis in FSW in Belgium 1998-2003

\begin{tabular}{lllll}
\hline & No of people tested & No of episodes & $\begin{array}{l}\text { No of episodes/ } \\
\text { No of people tested }\end{array}$ & 95\% Cl \\
\hline 1998 & 122 & 11 & $9.0 \%$ & 3.9 to 14.1 \\
1999 & 143 & 13 & $9.1 \%$ & 4.4 to 13.8 \\
2000 & 210 & 13 & $6.2 \%$ & 2.9 to 9.4 \\
2001 & 263 & 21 & $8.0 \%$ & 4.7 to 11.3 \\
2002 & 294 & 20 & $6.8 \%$ & 3.9 to 9.7 \\
2003 & 315 & 20 & $6.3 \%$ & 3.7 to 9.0 \\
& 1347 & 98 & $7.3 \%$ & 5.9 to 8.7 \\
\hline
\end{tabular}

\section{Key messages}

- The prevalence of $C$ trachomatis in female sex workers in Belgium is higher than in women of comparable age in the general population

- Screening of sex workers for $C$ trachomatis should start from the very beginning of their starting work in sex industry

higher than reported in the Czech Republic ${ }^{6}$ (5.5\%, not corrected for age). The prevalence was higher than in populations selected in general practices in Belgium ${ }^{7}$ (12.4\% $v 6.6 \%$ in $18-22$ year olds, $7.9 \%$ v $5.8 \%$ in $23-27$ year olds, and $4.7 \% \vee 3.3 \%$ in $28-40$ year olds), in home obtained urine specimens for the general population in Britain $^{8}(11.5 \% \mathrm{~V}$ $3.0 \%$ in $18-24$ year olds, $5.6 \% \vee 1.7 \%$ in $25-34$ year olds and $3.5 \% v 0.6 \%$ in $35-44$ year olds), and the Netherlands ${ }^{9}(15.0 \%$ $v 2.4 \%$ in $15-20$ year olds, $9.3 \% v 4.4 \%$ in $21-25$ year olds, and $5.3 \% v 2.5 \%$ in $31-35$ year olds).

Age was the strongest risk factor for $C$ trachomatis. Young women in general have the highest chlamydia incidence, which is related to their experimental phase in forming sexual relationships. For sex workers, the risk of sex work adds to the risk in their private life.

Over the 6 year period, there was no clear tendency of changing prevalence. Only a small fraction of the total number of women had a yearly test in the project. The reason for this is the high turnover of this population. There is a constant influx of new women and many women leave the trade after some time. Since younger age is a risk factor for $C$ trachomatis, it is very important to contact these women as soon as possible when they enter the trade. Risks outside of sex work should be discussed ${ }^{10}$ and partners treated. ${ }^{11}$ Good communication is a prerequisite. General screening for $C$ trachomatis in young women is not common practice in Belgium. Sex workers will often not tell the doctor about their work in the sex industry, and will therefore not be screened unless in the context of specific outreach projects.

\section{ACKNOWLEDGEMENTS}

The project was financed by the Ministry of Health of Flanders, the Province of East Flanders, and the City of Ghent. We would particularly like to thank all women for their trust in the project.

\section{CONTRIBUTORS}

RM is the principal investigator; LVR performed and interpreted the tests; AT collected most of the samples.

\section{Authors' affiliations}

R P Mak, Department of Public Health, Ghent University, De Pintelaan 185, 9000 Ghent, Belgium

L V Renterghem, Laboratory of Bacteriology and Virology, Ghent University Hospital, De Pintelaan 185, 9000 Ghent, Belgium R P Mak, A Traen, PASOP VZW, Sex Workers Health Centre, Brabantdam 100B, 9000 Ghent, Belgium

Correspondence to: R P Mak, Department of Public Health, Ghent University, De Pintelaan 185, 9000 Ghent, Belgium;

Rudolf.mak@ugent.be

Accepted for publication 13 May 2004

\section{REFERENCES}

1 Holmes K, Mardh P, Sparling P, et al. Sexually transmitted diseases. 3nd ed. New York: McGraw-Hill Book Company, 1999.

2 Pimenta J, Catchpole M, Gray M, et al. Evidence based health policy report. Screening for genital chlamydial infection. BMJ 2000;321:629-31.

3 Mak R, Traen A, Claeyssens $M$, et al. Hepatitis B vaccination for sex workers: do outreach programmes perform better? Sex Transm Inf 2003;79:157-9.

4 Matteelli A, Beltrame A, Carvalho AC, et al. Chlamydia trachomatis genital infection in migrant female sex workers in Italy. Int J STD AIDS 2003;14:591-5.

5 Esquivel CA, Briones Ezcarzaga ML, Castruita Limones DE, et al. Prevalence of Chlamydia trachomatis infection in registered female sex workers in northern Mexico. Sex Transm Dis 2003;30:195-8.

6 Resl V, Kumpova M, Cerna L, et al. Prevalence of STDs in Czech border areas with Germany in 1997-2001 assessed in project "Jana". Sex Transm Infect 2003;79:E3.

7 Verhoeven V, Avonts D, Meheus A, et al. Chlamydial infection: an accurate model for opportunistic screening in general practice. Sex Transm Infect 2003:79:313-17.

8 Fenton KA, Korovessis C, Johnson AM, et al. Sexual behaviour in Britain: reported sexually transmitted infections and prevalent genital Chlamydia trachomatis infection. Lancet 2001;358:1851-4.

9 Van Valkengoed IG, Postma MJ, Morre SA, et al. Cost effectiveness analysis of a population-based screening programme for asymptomatic Chlamydia trachomatis infections in women by means of home obtained urine specimens. Sex Transm Infect 2001;77:276-82.

10 Ward H, Day S, Weber J. Risky business: health and safety in the sex industry over a 9-year period. Sex Transm Infect 1999;75:340-3.

11 Postma M, Welte R, Van den Hoek A, et al. Opportunistic screening for genital infections with Chlamydia trachomatis among the sexually active population of Amsterdam. III. Cost-effectiveness analysis of screening women and the role of re-infection and partner treatment. Ned Tijdschr Geneeskd 1999; 143:2383-5. 